\title{
Research on the Correlation Model of Network Load Index in Mobile Packet Domain under the Background of Network Integration
}

\author{
Zhang Xidong ${ }^{1, a^{*}}$, Lai Guojun ${ }^{1, b}$, Zhang Heng ${ }^{1, \mathrm{c}}$, Chen Hao ${ }^{1, \mathrm{~d}}$, Zhao Yang ${ }^{1, \mathrm{e}}$ \\ ${ }^{1}$ Army Aviation Institute, $9^{\text {th }}$ Taihu Street, Tongzhou District, Beijing, China \\ ascience_storm@163.com, ${ }^{b}$ laiguojun@hotmail.com, 'st0rm@126.com, ${ }^{d}$ st0rm@163.com, \\ ezhengju1313@163.com
}

Keywords: Mobile packet domain, Network load index, Backbone network

Abstract. According to the network data of mobile packet domain in backbone network, this article analyzes the correlation model of network load index in mobile packet domain. Based on the mobile service and analysis model of user behaviors, in this paper we proposed a correlation model and curve model on total traffic and average sessions, providing a theoretical support for the monitoring and traffic grooming of backbone network.

\section{Introduction}

With the development of mobile communication technology, traditional speech communication service of communication network has already tended toward saturation. The main service of network is under transformation: the volume of voice service that charges by hour declines gradually and SMS, which bases on voice communication, also has a declining tendency. Mobile data flow thus has obtained a significant growth due to the rapid application of smart terminal as well as the diversity of mobile data service.

The explosive growth of traffic volume has greatly impacted communication network, forcing the network manager to improve and strengthen existing network, while balancing the contradiction between traffic growth and network bearing capacity through various approaches.

Hence, based on the network load index and relevant data of mobile packet domain of certain telecommunication network administer in China, it is of certain practical and theoretical significance that this paper applies regression analysis to construct a correlation model of network load index in mobile packet domain, and provides certain reference for the traffic grooming and monitoring of network in mobile packet domain in the future.

\section{Analysis on the Network Service and Correlated Index of Mobile Packet Domain}

Analysis model of User Behavior of Mobile Data Service. To realize a stable and sound development of mobile data service, it not only needs to rely on the innovation of technology and service, but to learn of client's feeling and behavioral characteristics after using service, and lay particular emphasis on service implementation. Thus, it is necessary to establish a set of effective method system so as to analyze user's behaviors as it can provide front-end department with data basis and analysis method to guide business operation on the one hand, and offer macro business information to people of management level for development strategy.

This paper describes the development condition of mobile data service of each region in the form of quadrant diagram, and analyzes from the relations between user number and user online hours, between user online hours and total traffic, and between user number and total traffic. From the development of mobile data service, the relation between user number and user online hours can accurately and effectively reveal the development condition of mobile service in each area and the value of newly-added users. With the increase of data service users, network administrator's maintenance cost will increase accordingly. 


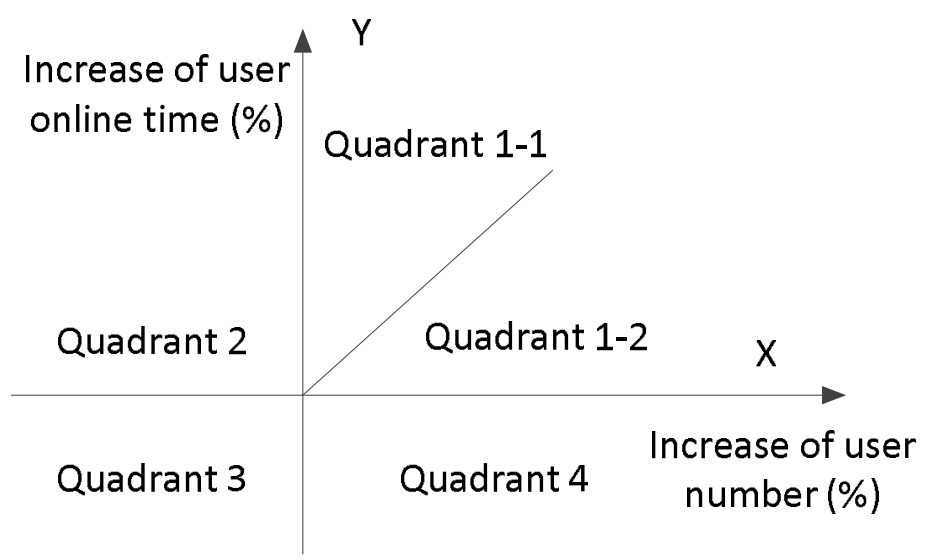

Fig. 1 Relational Graph of User Number of Mobile Data Service and User Online Hours

In Fig. 1, abscissa represents the development condition of user numbers in each region, while the growth range or reduction range (percentage) of this month compared with last month is taken as unit; ordinate represents the development condition of user online hours of mobile data service in each region, while the growth range or reduction range (percentage) of user online hours in this month compared with last month is taken as unit.

Quadrant 1-1: The growth range of user numbers is greater than that of user online hours, revealing a sound condition of business development in this region. In terms of value, however, the value of the newly-added users of mobile data service is lower compared with that of old users.

Quadrant 1-2: The growth range of user is smaller than that of user online hours, revealing the value of newly-added users of mobile data service is higher and the development condition of mobile data service is sound.

Quadrant 2: when the online hours of mobile data service in the current month increases but the user number of mobile data service decreases, it is needed to adjust price policy rationally or irrational monthly package so as to prevent the decrease of data traffic users.

Quadrant 3: User numbers and online hours are in a negative growth, revealing a shrinking mobile data service.

Quadrant 4: The user number has increased while the user online hour has cut down. From user behavior, it reveals that the user value of mobile data service is fairly low, which is required to adjust the price policy of irrational service.

Through certain types of business data and analysis of user behavior, it discovers that certain correlation is existed between user behavior and online hours flow. Therefore, further analysis is conducted on the relations of load index in mobile packet domain in an effort to study the relation between user behavior and load index.

\section{Correlation Model of Average Business Volume Processed by SGSN and Average Sessions}

\section{Correlation Model of Average Business Volume Processed by SGSN and Average Session under}

Gb Mode. It can be seen from Table.1 that the Pearson coefficient of average business volume of GTP data possessed by SGSN and average session activated by Gb mode is 0.820 , and is very significant under 0.01 confidence level. Thus, it can deduce that significant correlation relation is existed in average business volume of GTP data processed by SGSN5 and average session activated by Gb Mode. Regression analysis is further conducted to ensure its correlation model. 
Table.1 Correlation Analysis of Average Business Volume Processed by SGSN and Average Sessions under Gb Mode

\begin{tabular}{|c|c|c|c|}
\hline & & $\begin{array}{c}\text { Average Business } \\
\text { Volume of Processing } \\
\text { Data }\end{array}$ & $\begin{array}{c}\text { Average Session } \\
\text { Activated by Gb Mode }\end{array}$ \\
\hline \multirow{3}{*}{$\begin{array}{l}\text { Average Business Volume of } \\
\text { Processing Data }\end{array}$} & Pearson Correlation & 1 & $.820^{* *}$ \\
\hline & Sig. (2-tailed) & & .000 \\
\hline & $\mathrm{N}$ & 746 & 746 \\
\hline \multirow{3}{*}{$\begin{array}{l}\text { Average Session Activated by Gb } \\
\text { Mode }\end{array}$} & Pearson Correlation & $.820^{* *}$ & 1 \\
\hline & Sig. (2-tailed) & .000 & \\
\hline & $\mathrm{N}$ & 746 & 746 \\
\hline
\end{tabular}

Average Business Volume of Data Processed by SGSN

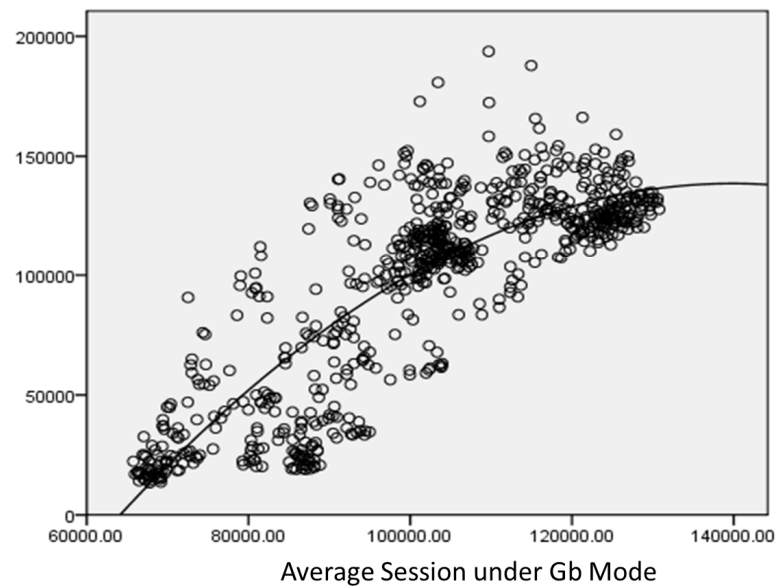

Fig. 2 Curve Analysis on the Average Business Volume of Data Processed by SGSN and Average Session under Gb Mode
Average Business Volume of Data Processed by SGSN

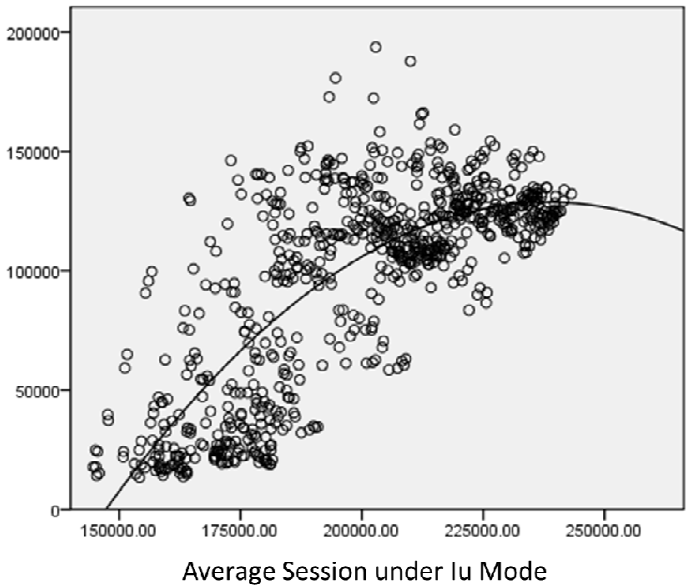

Fig. 3 Curve Analysis of Average Business Volume of Data Processed by SGSN and Average Session under Iu Mode

The quadratic model is: $y=-334000+6.785 x-2.416 \mathrm{E}-5 \times 2$, and the quadratic coefficient is $-2.416 \mathrm{E}-5<0$, indicating that the GTP data business volume processed by SGSN will decline when the average session reaches certain value under $\mathrm{Gb}$ mode in the network system, and the turning point can be calculated as 280836 . Therefore, it can be seen that curve model, as a matter of fact, is better than the linear model.

Correlation Model of Average Business Volume of Data Processed by SGSN and Average Session under Iu Mode. It can be seen from Fig. 3 that the Pearson coefficient of average business volume of GTP data processed by SGSN and average session activated by Gb Mode is 0.820 , and is very significant under 0.01 confidence level. Thus, it can deduce that significant positive correlation relation is existed in the average business volume of GTP data processed by SGSN and average session activated by Gb mode. Regression analysis is further ensured for its correlation model. 
Table. 2 Average Business Model of Data Processed by SGSN and Average Session under Iu Mode

\begin{tabular}{|c|c|c|c|}
\hline \multirow{1}{*}{$\begin{array}{c}\text { Average Business Volume of Data } \\
\text { Processing }\end{array}$} & $\begin{array}{c}\text { Average Business } \\
\text { Volume of Data } \\
\text { Processing }\end{array}$ & $\begin{array}{c}\text { Average Session } \\
\text { Activated by Iu Mode }\end{array}$ \\
\cline { 2 - 4 } & Pearson Correlation & 1 & $.741^{* *}$ \\
\cline { 2 - 4 } & Sig. (2-tailed) & & .000 \\
\hline \multirow{2}{*}{$\begin{array}{c}\text { Average Session Activated by Iu } \\
\text { Mode }\end{array}$} & Pearson Correlation & 746 & 746 \\
\cline { 2 - 4 } & Sig. (2-tailed) & $.741^{* *}$ & 1 \\
\cline { 2 - 4 } & $\mathrm{N}$ & 746 & 746 \\
\hline \multirow{2}{*}{$* *$ Correlation is significant at the 0.01 level (2-tailed). } & & \\
\hline
\end{tabular}

Quadratic model: $y=-752500+7.393 x-1.551 E-5 x 2$, quadratic coefficient is $-1.551 \mathrm{E}-5<0$, indicating that the business volume of GTP data processed by SGSN will decline when the average session reach certain value in the network system under Iu mode. In addition, the turning point is 476660 . Therefore, it can be seen that the average business volume of data processed by SGSN will not increase with the increase of average session under Iu mode if the number of average session is greater than this value.

\section{Summary}

It can be found from the analysis on the loan index of mobile network that in the data monitoring of current network, the average session under Gb mode should be controlled within the scope of 197750-280836, where total traffic processed by SGSN will not be too large when the business volume processed by SGSN is large. This also means that the network resource can be taken full advantage while it will not overload the network. From the analysis of correlation model above, this article obtains that the reasonable interval of average session under $\mathrm{Gb}(2 \mathrm{G})$ model is $197750-280836$, and under Iu Mode is 303430-476660. These theoretical values can be regarded as reference on whether expansion is needed on network.

\section{References}

[1] Zhao Chunlian, Yu Anping, Analysis on the Factors Affecting the Customer Value of Mobile Communication Enterprise [J]. Value Engineering. 2006(01):55-57

[2] Li Lei, Xin Zhanhong, Optimal Model for Business Investment of Telecommunication Network Administer [J]. Academic General of Chongqing University of Posts and Telecommunications (Social Sciences Edition) 2008(02):17-19

[3] Yang Mengke, Zeng Jianqiu, Research on the User Mobile Business Evaluation Model of Telecommunication Operation Enterprise [J]. Academic General of Chongqing University of Posts and Telecommunications (Social Sciences Edition) 2013(06):55-59

[4] Li Jianzhou, Zong Xinhua, Che Liwei, Evolution and Outlook on the Digital Channel of Network Administer [J]. Mobile Communication. 2010(21):38-41

[5] Zhang Changqing. Analysis on the Core Network Technology of TD-LTE Evolution Type Packet Domain [J], Mobile Communication. 2013(08):51-56 